\title{
¿Geoficción? Ciudades en la Galaxia
}

\author{
Emilia García Escalona y Felipe Hernando Sanz \\ Departamento de Geografía Humana \\ Universidad Complutense de Madrid \\ egarciae@ghis.ucm.es y fjhernan@ghis.ucm.es
}

Recibido: 30 de septiembre de 2011

Modificado: 27 de octubre de 2011

Aceptado: 30 de octubre de 2011

"Trántor, Haven, Haven II, Newton, Radole City, Gleiar City, Kalgan..."

(Isaac Asimov, Trilogía de la Fundación)

\section{Resumen}

La geografía ha buscado constantemente espacios para describir y analizar. De los reales a los de las imágenes, y más recientemente a la imagen en la literatura o el cine, pero con menor frecuencia se ha ocupado de las imágenes proporcionadas por la ciencia ficción. Planteamos en este artículo una lectura desde la geografía de la Trilogía de la Fundación de Isaac Asimov, una narrativa de hace seis décadas que nos ha permitido analizar las prospecciones en el espacio urbano. Sin duda, la ficción del autor es contemplada desde la realidad urbana actual, la evolución del pensamiento geográfico y nuestra subjetividad.

Palabras clave: ciudades, espacios urbanos, geografía urbana, Trilogía de la Fundación, Isaac Asimov.

Title: Geofiction? Cities in the Galaxy

\section{Abstract}

Constantly, geography has explored spaces to describe and analyze. From the real space, to the images; and more recently, to the image in literature or film, but less frequently has addressed the images provided by science fiction. We propose in this article, a reading from the geography of the Foundation Trilogy by Isaac Asimov, a narrative of the past six decades; that has allowed us to analyze the surveys in the urban space. The author's fiction is examined from the current urban reality, the evolution of geographical thought and our subjectivity.

Keywords: cities, urban spaces, urban geography, Foundation Trilogy, Isaac Asimov.

\section{Índice}

1. Introducción

2. Ciudad

2.1. Neo-miradas y neologismos

2.2. Ciudad y ciencia ficción

2.3. Espacio: virtual, ciber y post

3. Ciudades: Trilogía de la Fundación 


\section{Introducción}

La galaxia urbanizada imaginada por Asimov en su Trilogía nos permite comparar el futuro urbano creado por la ciencia ficción, mediado el siglo XX, con la realidad de las ciudades en la actualidad. Desde la geografía, nos acercaremos a la literatura de ficción, animados por la existencia de trabajos que "ofrecen un itinerario por la escritura de lo urbano, con la promesa de una participación activa en la construcción novedosa de una imagen literaria y cinematográfica de la vida cotidiana" (Popeanga 2010: 7). Esta lectura nos ha llevado a un itinerario geográfico por ciudades de ficción, permitiéndonos conocer sus singularidades, características, y particulares espacios públicos y privados.

El profesor Burton Pike señaló que "la sociología urbana está saturada de metáforas y prefiere hablar de megalópolis, conurbación, o área de desplazamientos diarios, más que de ciudad; términos que pueden representar más una proyección de actitudes culturales que una descripción neutral de la realidad" (1981: 130). Efectivamente, sociólogos, geógrafos, urbanistas, etc., frente al crecimiento urbano de considerable expansión y diversidad de formas, han ido inventando palabras que intentan conceptualizar la pluralidad de formas de la ciudad actual, tratando de capturar su multidimensionalidad, obviando el tiempo y los mitos:

En nuestras ciudades occidentales modernas vivimos en espacio pero pensamos en tiempo. [...] Concebida subordinada al tiempo, la ciudad como una imagen sólo puede consistir en espejos o espejismos, que constantemente se refractan y reflejan las luces cambiantes y los ángulos en el tiempo. (Pike 1981: 135-136)

Desde que existe la literatura, han existido ciudades en la literatura [...] no solo considerando este fenómeno moderno, no podemos imaginar Gilgamesh, la Biblia, la Ilíada, o la Eneida, sin sus ciudades, que contienen tanto de su energía e irradian tanto de su significado. [...] El doble paisaje de la ciudad real y la ciudad mítica no es tan misterioso como aparece a primera vista, puesto que todos los mitos son intentos de explicar la realidad. (Pike 1981: 3,7)

En este sentido, la mejor introducción al Berlín postmoderno probablemente sea la imagen reflejada en espejos que proporciona la gran columna especular del interior de la cúpula del Reichstag (Norman Foster), permitiendo múltiples miradas sobre la ciudad y proyectando, al mismo tiempo, escenario urbano e imagen de los visitantes, que al caminar por la rampa, además de parecer espejismos, se contraponen a la visión real urbana que se tiene desde la propia terraza del edificio. 


\section{Ciudad}

\subsection{Neo-miradas y neologismos}

El recurso a la narrativa y a los neologismos es cada vez más frecuente para tratar de capturar la ciudad actual. David Harvey cita con frecuencia a Raban en su "indagación sobre los orígenes del cambio cultural"; en el capítulo que dedica al postmodernismo en la ciudad, considera que "los entornos construidos postmodernos por lo general buscan y repiten deliberadamente temas que Raban enfatizó con fuerza en Soft city" (Harvey 1990: 83). Sin embargo, el Londres que encontró y describió Raban (1974), una ciudad blanda, mereció una dura crítica (en la revista de libros del Geographical Journal) por parte del geógrafo y urbanista londinense Peter Hall: "es un libro subjetivo, su Londres es una ciudad de extranjeros, soñando sueños aislados, el símbolo de la soledad está en todas partes" (Hall 1975). Pero todas estas voces nuevas se incorporan como conceptos, y dan lugar a trabajos como Mumbai: the Soft City (Luke 2008: 32).

La geografía es hoy plural en temas, herramientas, territorios a explorar, "tras abandonar la unidad de los conocimientos", según escribe Harvey en el año 2000, al abrir a la comunidad geográfica Espacios de esperanza: "en tiempos recientes se ha abandonado dicha unidad en las humanidades e incluso en la mayoría de las ciencias sociales" (Harvey 2003: 258), y así, él mismo recurre a las utopías en la literatura y en el urbanismo, a metáforas, a la literatura -Trilogía de Marte, El año 2000 (Harvey 2003: 220)- y al cine -El odio y Dos o tres cosas que sé de ella- para explicar "la diferencia que supone una generación" en la ciudad (Harvey 2003: 20-24). Fuera de la geografía, algunos autores han utilizado el concepto de "ficción en el paraíso", proponiendo un sutil y atractivo juego de palabras, para referirse al cine; no solo como uno de los vuelos más audaces que ha proporcionado la imaginación del ser humano, sino también como continente e impronta constructiva de nuestras ciudades, que tiene su manifestación en las salas grandes de cine, que pueden llegar a ser consideradas como catedrales y constituyen "un elemento importante en la metamorfosis de la realidad urbana" (Castellani 2010: 173-186).

Las ciudades actuales son inimaginables. Podemos realizar inventarios, fraccionarlas temáticamente, intentar reconstruirlas a base de cartografiar capas. Son muchas las lecturas que tiene la ciudad.

Hay mucho más en la ciudad que lo visible, sentimientos, tal vez, o tal vez un sentido de las relaciones sociales de la ciudad [...]. Si sabemos algo acerca de las ciudades, quizás es que son demasiado inmensas para ser imaginadas en su totalidad, es decir, como una ciudad [...] iStop! Cierren sus ojos. Imaginen una ciudad. (Pile y Thrift 2000) 
Es lo que estos autores nos indican en la "guía para los lectores" de su City $a-z$, y proponen cuatro maneras de leer su abecedario urbano; pues bien, si hay cuatro maneras de leer su volumen, hay infinitas maneras de conocer la ciudad y lo urbano. Una de las posibles es mirar la ciudad, su paisaje y la sociedad a través de la narración literaria o cinematográfica, porque hay que recurrir a la imaginación ante la nueva ciudad y sus variadas denominaciones: tecnopólis, postsuburbia, metroplex, ciudades de borde (edge cities), Silicon landscapes, 100 miles city, exópolis, cybercities. Hay que buscar un modelo urbano más allá de Chicago, buscar el molde postmoderno, "poner a Los Ángeles primero" (Soja 2008: 24) para explorar las postmetrópolis. Asimismo, entre las nuevas denominaciones destaca City of quartz. Excavating the future in Los Angeles (1990); que en su primer capítulo, a modo de introducción, analiza la visión de "los intelectuales de Los Ángeles", y dedica algunas páginas (Davis 2003: 19-29) al género negro, a la ciudad angelina en la novela y en el cine; en su prólogo, describe "la galaxia urbana bajo la influencia de Los Ángeles".

Una superficie construida que equivale aproximadamente al tamaño de Irlanda y un producto interior bruto mayor que el de la India, es la metrópolis de crecimiento más acelerado en el mundo industrializado. Su población actual es de quince millones, comprende seis condados y una porción de la Baja California, y se agrupa en torno a dos megacentros (Los Ángeles y San Diego-Tijuana) y una docena de grandes centros urbanos en expansión; se prevé que, para la próxima generación, la población aumentará en siete u ocho millones. La inmensa mayoría de estos nuevos habitantes no serán anglosajones, lo que alejará aún más el balance étnico de la hegemonía de los wasp y lo inclinará hacia la diversidad multiétnica del próximo siglo. (Davis 2003)

Referencias a la novela e imágenes cinematográficas se encuentran cada vez más en la geografía, ya que:

A través de la historia, imágenes utópicas y distópicas han caracterizado el discurso de la ciudad; Nuestra comprensión del orden y desorden urbano, está fuertemente influenciado por los media, la imaginería de la televisión y el cine. [...] Imágenes distópicas se encuentran en numerosas películas producidas por Hollywood. (Pile, Brook y Money 1999: 351, 364)

La primera frase que Pacione escribe en su manual Urban geography, a global perspective es: "el mundo contemporáneo es un mundo urbano"; el trabajo remite a Blade Runner para tratar el significado de la ciudad virtual (Pacione 2001: 593) y recoge en el abundante glosario, junto a otros términos que hemos citado 
anteriormente, los vocablos: cyberbia, exurb, nimby-ism, rural-urban continuum, soft state.

\subsection{Ciudad y ciencia ficción}

Narrativa literaria y fílmica y ciencias sociales se entremezclan, tratando de ver indistintamente ficción y realidad o realidad y ficción, una realidad de difícil aprehensión a comienzos del tercer milenio. La ciudad en la ciencia ficción es tratada desde la sociología, "intentando mostrar un marco de similitudes entre la Ciudad que alguna literatura de ciencia ficción y aquella que cierta lectura del urbanismo moderno pretendió construir" (Peña 2002: 3). Con imágenes procedentes de la fotografía, la pintura, la narrativa y el cine se analizan el control y la vigilancia del espacio urbano desde la filosofía (Cortés 2010). Viajar para describir la tierra y andar el espacio urbano, esencial en la geografía, parece haber sido recogido por la arquitectura, si tenemos en cuenta la transurbancia que Stalker / Observatorio nomade practica, recuperar el flâneur, el andare a zonzo. Stalker, iniciado por Careri y Romito, toma el nombre de una novela de ciencia ficción, y ante la falta de conocimiento de las ciudades, pone en práctica paseos urbanos con lectura psicogeográfica, así el libro de Careri se denomina Walkscapes (2002).

Como otras ciencias sociales, la geografía ha hecho uso de textos literarios, y un buen ejemplo de esquema metodológico para el estudio del territorio en la literatura de creación es el propuesto por Carreras (1998: 163-176) al asumir la subjetividad del autor. La literatura proporciona técnicas de expresión y recursos de lenguaje e imágenes imprescindibles para la investigación geográfica; las descripciones e interpretaciones literarias constituyen un elemento importante en la explicación de la realidad territorial y permiten avanzar en su comprensión. Este tipo de fuentes son complementarias en el momento actual "en que se carece de datos fiables sobre el presente y futuro inmediato de nuestro mundo" (Carreras 1998: 175).

La ruptura de la rigidez científica ha permitido una geografía más humanizada, que se aproxima a la subjetividad humana con el uso de obras literarias o del cine, y la aplicación de técnicas cualitativas. "El acercamiento de la geografía al cine es algo novedoso desde el punto de vista científico, y por lo tanto es una tarea arriesgada. El cine, por el contrario, vive inmerso en la geografía, aunque generalmente no piensa en ella" (Córdoba 1998: 178).

Asimismo la imagen de las películas de ciencia ficción se analiza mediante el tratamiento de los espacios urbanos funcionales en el cine y el tránsito desde utopía hacia distopía, pero en este caso se parte de conceptos sobre el espacio urbano (sociópolis, megápolis, mecanópolis, tiranópolis, metápolis) y se concluye con una opción optimista: "será en esa ciudad del futuro, dispersa, consumista, 
privatizada, luminosa y divertida, donde se produzca la ruptura definitiva del tejido social, cada vez más mediatizado por mecanismos electrónicos interpuestos. Conviene pues que el cine comprometido con el futuro de la Humanidad reajuste su punto de mira" (Ponce 2011: 150). Desearíamos, como nuestro colega, esa ciudad futura, pero por el momento vivir en espacios urbanos conlleva luces y sombras; y la ciudad multicolor se contempla en blanco y negro, como algo bueno $y$, a la vez, malo. Asistimos a cambios en tiempo virtual; guetos poco recomendables que se transforman en atractivos urban villages; páramos poco productivos que terminan constituyendo una ciudad financiera; centros comerciales disneyficados; polígonos, originalmente industriales, transformados en almacenes comerciales chinos; barrios producto de la inmigración nacional convertidos en chinatown; y eso con tan solo mirar una aglomeración media a escala global: Chueca, Banco Santander, Las Rozas Village, Cobo Calleja (Fuenlabrada), Pradolongo y Moscardó (distrito de Usera); y las miradas ante estas transformaciones son igualmente blancas y negras.

Efectivamente estamos ante otras ciudades, derivadas del fantástico avance tecnológico y de la imaginación de la mente humana.

\begin{abstract}
A la pregunta de qué es una ciudad podría responderse, en estos tiempos resueltos: lo mismo que una novela. Ambas -ambos géneros- tienen sus límites igual de difusos a la vez que sus contenidos manifiestan una tendencia a la indefinición, más una cierta resistencia a los moldes. Lo cual, como se observa, no es decir gran cosa. Pero lo cierto es que se trata de objetos poco interpelables en los términos tradicionales, porque nacen precisamente de una descomposición de esos mismos términos tradicionales y de sus realidades adjuntas. (Gándara 2003: 45)

[...] De la Historia de Roma de Gibbon a la saga de la Fundación de Isaac Asimov, tenemos el sentimiento de que el tiempo nos enseña, aparte de mostrarnos, y que quien no aprende del pasado lo paga en su presente, por decirlo con un tópico. (Gándara 2003: 9)
\end{abstract}

\title{
2.3. Espacio: virtual, ciber y post
}

La hiperrealidad actual se gobierna desde un espacio nuevo, el ciberespacio, término atribuido a un cuento de ciencia ficción, Nuromante (Gibson 1984), que explica en palabras de Soja su introducción en la ciencia:

Hace más de cuarenta años empezó a ser usado en inglés prominentemente, con el fin de definir la nueva ciencia "cibernética", el estudio del control y de las comunicaciones tanto en los organismos vivos como en las máquinas, a través de lo que se llamó la "teoría de la información". En la consecuente evolución del ciber- 
discurso, los cibernéticos comenzaron a engendrar una completa y extensa familia de términos que nombraban la apertura a un nuevo mundo generado tecnológicamente de CMC (comunicaciones mediadas por ordenador), que vino cada vez más relacionado con las nociones relativas a la hiperrealidad (a menudo con nodos filosóficos, como Baudrillard). Con la unión de ciber- y espacio, sin embargo, la cibernética fue especializada explícita y asertivamente en algo más que en meros términos metafóricos. Si bien hoy en día rara vez se menciona la cibernética, el ciberespacio ha capturado el propio núcleo de la conciencia popular y está modelando de forma profunda la cultura contemporánea del espacio y del tiempo en el pasaje al siglo XXI. (Soja 2008: 464)

El diferente tiempo en la introducción cultural del término cyber, se comprueba con la profusión de vocablos en la cultura actual. En inglés, en la consulta on line del Diccionario de Oxford, The Oxford English Corpus contiene más de veinte acepciones de cyber-; en el Diccionario de la RAE (vigésimo segunda edición), a ciber- se le asignan tan solo: ciberespacio, cibernauta, cibernética, cibernético. Los neologismos son abundantes para explicar la ciudad y sus atributos, véase el glosario que proporciona el Centro Andaluz de Arte Contemporáneo (2006-2011), porque la ciberciudad "no sólo desdibuja los límites entre la realidad en red y la presencial, sino que también desmenuza las diferencias que hay entre las diferentes disciplinas que centran su foco de atención en las urbes, en el contexto de la sociedad de la información" (López 2007: 2).

Efectivamente, las múltiples manifestaciones del hecho urbano exigen visiones y disciplinas distintas que las estudien, como propone La ciudad objeto de estudio pluridisciplinar (García Ballesteros 1995). Ante la urbe del siglo XXI debemos considerar que "la ciudad en su sentido clásico, ya no existe, pero en su lugar se está construyendo un simulacro de ciudad clásica muy convincente. Y este simulacro es verdadero" (Azúa 2004: 180). Realmente, nos desafía "una ciudad de múltiples dimensiones, dispersa y discontinua, fragmentada en una pluralidad de núcleos y de formas, y para abordarla, la cultura urbanística del siglo XXI tiene sólo respuestas y conceptos dispersos" (Borja 2003: 98).

Por lo tanto, va siendo frecuente la inclusión de los virtual, ciber- y post-espacios como paisajes objeto de investigación, y penetran en nuestras mentes de muy diferentes maneras porque:

1) "En la configuración de las nuevas ciudades dispersas juega un papel fundamental la imagen virtual de los valores culturales relativos a lo urbano y a lo rural", como señala C. Ferrás en su artículo "La ciudad dispersa y las aldeas virtuales" (1999: 1035), y Zaragoza es Zaragoza virtual (Gómez de Segura et al. 2007).

2) "El ciberespacio es percibido efectivamente como espacio" (Gutiérrez 2000: 528). Con las tecnologías digitales, la geografía 
tendrá nuevos desafíos: la cibergeografía (Buzai 2004); Barcelona es "una ciberciudad en tránsito" (Vivas et al. 2008), y el ciberespacio ha sido cartografiado en el Atlas of Cyberspace, en el que se han conjugado los conocimientos de un experto en computadores y de otro en geografía humana, imaginando el ciberespacio y enfatizando que:

Igual que el ciberespacio es una transformación tecnológica, cambiando la manera en que vivimos nuestras vidas, la ciencia ficción que ha considerado el ciberespacio está escrita en un nuevo género, uno que trastorna su tradición moderna. El Cyberpunk reconoce y explora nuestra nueva condición postmoderna a través de un vehículo literario que es, él mismo, decididamente postmoderno. (Dogge y Kitchin 2001: 229)

3) El prefijo post conlleva en su práctica novedad, crítica, o conceptualización, y lo encontramos desde la Postmetrópolis (Soja 2008), en una "estrategia de revitalización urbana" (Juaristi 1999), o incluso en el libro y la exposición itinerante Post-it City. Ciudades ocasionales (CCCB 2008).

Por otra parte, del mismo modo, también hay que considerar las relaciones que se dan entre ciudad y telecomunicaciones. La ciudad contemporánea es objeto de adjetivación y caracterización metafórica. Graham y Marvin (1996: 9) proponen hasta veinte, y para ellos la "ciudad está siendo redefinida y redibujada en ambos espacios, el físico y el electrónico" (Graham y Marvin 1996: 336); sin olvidar que "durante el siglo XX se ha ido generando una nueva forma de organización social que tiende a expandirse por todo el planeta, transformándolo en una nueva ciudad: Telépolis" (Echeverría 1999: 11).

La geografía ha descubierto otros territorios; eso parece cuando S. Graham (1998: 182) se preguntó por el fin de la geografía y, apostando por la recombinación de tecnología y lugar, presentó meramente el último proceso del urbanismo y no un simple posturban shift. También debemos recordar que en la ciudad del futuro que propone William Mitchell en su e-topía "los lugares físicos y los virtuales funcionarán de forma interdependiente $y$, en general, se complementarán mutuamente [...]. Algunas veces utilizaremos la red para no tener que ir a algún sitio; pero otras veces, todavía, iremos a algún sitio para establecer contactos" (Mitchell 2001: 164). El cambio tecnológico propicia transformaciones en el espacio, tendencias a la descentralización y la dispersión que coexisten con otras centralizadoras, "que favorecen particularmente a las grandes áreas metropolitanas, sobre todo a las ciudades globales, a las ciudades informacionales. Además se abren marcados contrastes dentro de las 
ciudades, entre enclaves superconectados y áreas que virtualmente quedan fuera de la red" (Gutiérrez 2003: 129).

Elementos visibles de la aplicación de las nuevas tecnologías se pueden observar en el panorama urbano actual (cámaras de vigilancia, conexión inalámbrica a internet anunciada por carteles, etc.); configuran los modernos panópticos y proponen visiones duales de la ciudad postmoderna: la ciudad del control frente a la ciudad de la información. Frente a ellos, hay otros elementos no visibles, que incluso parecen estar dando lugar a un modo de vida ciberurbano, si tenemos en cuenta el capítulo de The Cybercities Reader (Graham 2004) titulado "Cyburbanism as a way of life" (secuela ciber del Urbanism as a Way of Life publicado en 1938 por Louis Wirth).

Una reflexión del significado de estas prospecciones nos permite apuntar, por ejemplo, cómo y dónde se ha producido la conjunción de la tecnología popular (uso del móvil y las redes sociales, conexión a internet,...) y los espacios reales populares (plazas, calles y otros lugares públicos urbanos). Los acontecimientos sociopolíticos recientes del norte de África o España ilustran esta significativa confluencia.

Es evidente, a pesar de los augurios de algunos, destacar el valor que tienen los lugares físicos en lo que puede denominarse cyborg urbanisation (Graham y Marvin 2001: 184). Con tan solo mirar planos de localización de los dominios punto com en la ciudad de Boston en 1999 (Graham y Marvin 2001: 376), podemos observar su concentración en el downtown. En una reciente visión geográfica del ciberespacio, se incluye un mapa del ciberespacio de Buenos Aires que presenta similares polaridades que el anteriormente citado (Infantas 2009).

Las críticas al determinismo tecnológico son tan abundantes como las del papanatismo ante los aparatos, cada día más pequeños, más baratos y con más aplicaciones, que hacen olvidar el papel de la distancia, dejando de lado un hecho constatable, "que no siempre y en cualquier lugar" es fácil conectarse a la red. Muchos desatienden consejos como el de Harvey:

[...] es importante apreciar la volatilidad y el dinamismo de las formas geográficas contemporáneas. Ciudades y regiones metropolitanas (piénsese en Seúl o incluso en una ciudad de larga vida como Barcelona) que han sido reconfiguradas y transformadas geográficamente en el plazo de una generación. (Harvey 2003: 99)

Bien, pensemos que en África había dos ciudades de más de diez millones de habitantes en 2010, y que El Cairo pasará a ocupar un segundo puesto en 2020, cuando se proyecta que Lagos rebasará los catorce millones (Unhabitat 2011); y por qué no pensar en Madrid, en la inversión directa extranjera que llega a nuestra ciudad, 
en los inmigrantes que se ubican en toda la Comunidad, o en las transformaciones de nuestras infraestructuras. A modo de ejemplo, Asimov nos lleva a la M-30 cuando escribe: "durante largo rato, guardaron silencio en el taxi que les conducía, a través de cientos de kilómetros de túneles como gusanos, hacia la universidad" (Asimov 2010: 49).

Si la ecumenopolis y el ciberespacio fueron un futurible, hoy cada vez más parecen una realidad; habitamos espacios urbanos de diferentes escalas, el tiempo del día a día puede transcurrir en pocos metros o en muchos kilómetros, podemos socializarnos -o no- en el espacio o en el ciberespacio, y la geografía, ante la ciudad de hoy y el nuevo territorio humano, el "ámbito artificial creado por medios informáticos" (RAE), se enfrenta al desafío de su exploración con incertidumbre, al igual que otras ciencias. Ya se ha afirmado con relación al planeamiento de la ciudad y su arquitectura que:

En el contexto avanzado de la ideología tecnocrática serán desplazados por el nuevo "paradigma de la incertidumbre". Que, sin duda, desencadenará un visible cambio en la evolución y finalidades del proyecto ciudad. [...] En la metrópoli de hoy, nuestras miradas divagan por las autopistas del edén telemático, despojadas del efecto taumatúrgico, dotadas de una función de atemporalidad. Percepción y memoria se encuentran invadidas por este collage de inmateriales que igualan toda referencia, y donde ninguna escena o figura logra ser protagonista del cuadro. Palabras de la arquitectura, palabras de la geografía, palabras de la ingeniería, en definitiva, palabras de la ciudad. Los ámbitos del museo gráfico que constituye la ciudad de la información vienen cualificados por ese efecto pantalla encargado de difuminar los límites de nuestra realidad sensible, entre el ensueño que nos presta la fruición estética y la descarnada realidad. (Fernández de Alba 2006: 33, 57)

Al igual que, en su momento, deslumbró el fetichismo espacial, hoy parece resplandecer el determinismo tecnológico. Manuel Castells que, en 1989, en su Ciudad Informacional ya se mostró contrario al determinismo tecnológico respecto al futuro de la sociedad, en 2001 abre una ventana a los geógrafos.

La era Internet ha sido anunciada como el fin de la geografía. De hecho, Internet tiene una geografía propia, una geografía hecha de redes y nodos que procesan flujos de información generados y controlados desde determinados lugares. La unidad es la red, por lo que la arquitectura y la dinámica de varias redes constituyen las fuentes de significado y función de cada lugar. El espacio de los flujos resultantes es una nueva forma de espacio, característico de la era de la información, pero que no es deslocalizado: establece conexiones entre lugares mediante redes informáticas telecomunicadas y 
sistemas de transporte informatizados. Redefine la distancia pero no suprime la geografía. (Castells 2001: 235)

En este mismo trabajo, Castells (2001: 238, 243) incluye mapas de usuarios y de dominios de Internet a nivel mundial (julio de 2000), que son la plasmación de la diferencia entre desarrollo y subdesarrollo a inicios del presente siglo. El mapa reproducido en la página 246 presenta la distribución de dominios en la Región Metropolitana de Nueva York por código postal; su observación resulta ejemplarizante del valor de la centralidad. Manhattan exhibe los mayores valores, especialmente en Midtown y Uptown, y destaca el rectángulo en blanco (sin dominios) correspondiente a Central Park; por lo tanto, si "estamos entrando a toda velocidad en la Galaxia Internet" (Castells 2001: 18), estamos preparados para entrar en la Galaxia que Asimov proyectó en su Trilogía.

\section{Ciudades: Trilogía de la Fundación}

La introducción a la Trilogía, firmada por el polifacético Carlo Frabetti, se denomina "El ciclo de Trántor", y nos aclara el porqué de este título. "Es algo que entenderán perfectamente... en cuanto concluyan la serie" (Asimov 2010: 9). Efectivamente podíamos haber dedicado nuestro trabajo a Trántor, pero somos rehenes de nuestra trayectoria personal y profesional, y al igual que hay múltiples ciudades que visitar o estudiar, y diversidad de aproximaciones a la lectura de una novela, o al modo de ver el espacio urbano, intentamos hacer una lectura desde la geografía conscientes de que "hay una realidad, aunque cada uno la entendamos como nos venga en gana (o como le venga en gana a nuestro subconsciente, vaya)" (Moreno 2010: XI). El latifundio de Asimov no es global, es galáctico; y hay muchas ciudades en el mundo urbanizado de su Galaxia. Aunque Trántor es, por protagonismo en la obra, capítulos, demografía, funciones y poder, la cima de la ciudad galáctica. Por ello, nos planteamos si Trántor fue una prospectiva de la ciudad global -término que Sassen acuñó en 1991 en The global city: New York, London, Tokio ${ }^{1-}$, o bien si fue una prospectiva de otra metáfora de lo urbano enmarcada en los debates sobre las ciudades globales, la cosmópolis (Soja 2008: 328-331).

La Galaxia urbanizada que Asimov imaginó es un patchwork de ciudades y espacios urbanos, en ella podemos descubrir: supranacionalismo (supraplanetarismo), cultura híbrida (científicos, ciudadanos, y hasta campesinos que se ven afectados por el desarrollo y la tecnología), privatopia (vigilancia y espacios

${ }^{1}$ Estas aglomeraciones permanecen en su posición de la élite global en 2010, pero significativamente este es el mismo año en el que algunas ciudades asiáticas han escalado posiciones entre las diez primeras ciudades globales (Atkearnay 2011). 
prohibidos), polarización espacial (centro-periferia, a escala galáctica y urbana) e incluso ciudad-ocio.

Trántor es una ciudad postindustrial, una ciudad-mundo (su dominio alcanza a toda la Galaxia) y además constituye el centro del gobierno imperial; su posición física y funcional es central; es la capital del Imperio, y "aún más científica y culturalmente que por lo que a política se refiere"; tiene inmensos centros de venta al por menor, que en su parte superior albergan el mundo de las diversiones. No tiene espacios verdes, nada de tierra, ninguna otra vida más que la humana, solo el palacio imperial era un islote verde en un océano de acero.

Trántor tiene su réplica urbana en Neotrántor. Tras su gloria, vino el ocaso con la consecuente pérdida de poder, y así sus gentes volvieron a la primitiva agricultura y a vivir en pueblos. A Trántor, en su época de esplendor, se iba de vacaciones, de viaje, de visita a los lugares de interés, o a ocupar un empleo. El protagonista insiste en la idea de que "siempre había deseado venir a Trántor" (Asimov 2010: 28).

En cuanto a Kalgan, "Kalgan era... Kalgan". Por su clima, sus playas y las oportunidades de practicar diversos deportes, y también por sus alojamientos (hangares-hotel para naves), es la ciudad donde se puede experimentar "una buena luna de miel"; la ciudad donde buscar el escapismo inducido desde el mito y la fantasía; es la ciudad-ocio. Asimov conceptualiza el valor de la industria turística. "Era un mundo de recreo en el sentido de que convirtió la diversión en una industria provechosa, inmensamente provechosa, para ser más exactos". "Además era una industria estable, la más estable de la Galaxia"; evidentemente fue una ficción en los años cincuenta, hoy verídica si tenemos en cuenta que, en 2010, los destinos internacionales en todo el mundo registraron 600 millones de llegadas (OMT 2011).

Por otra parte, el autor alude a una clase privilegiada que se caracteriza por la "posesión del ocio, como única gran recompensa de su condición". Efectivamente en el planeta Tierra, la movilidad de sus habitantes no se realiza solo en busca de sustento, sino también por razones de ocio, y así se ha poblado de resorts; pueblos convertidos en pocas décadas en ciudades que viven por y para el turismo; puertos adaptados para el atraque de barcos; enclaves de ocio y de consumo donde se abren, al igual que en las metrópolis, millas de oro que dan albergue selectivo a firmas comerciales globales de lujo; residencias, con muelle propio, de países que explotan sus recursos naturales y culturales para adaptarse no a la revolución industrial moderna, sino a la muy postmoderna industria del turismo, producida por el también postmoderno consumismo de mercancías, servicios y experiencias. Si "la ciudad toda se convierte en shopping mall" (Amendola 2000: 216), el consumo de experiencias lleva incluso a 
buscar espacios extraterrestres, y si estamos en un desajuste espacial que ha dado lugar a la ciudad fractal, existe "la fábrica de la desigualdad en la postmetrópolis" (Soja 2008: 373-418).

Del mismo modo que las calles, paseos y playas, clonando los malls se llenan de locales comerciales del top-manta, con empleados informales, productos baratos, copias ilegales e imitaciones de lujo, sus clientes practican el simulacro del consumo. En esos mismos espacios, otros buscan sobrevivir mostrando sus desgraciadas condiciones físicas o sociales. La desigualdad se acentúa en cualquier territorio y afecta a los verdaderamente desfavorecidos. "Kalgan era el mundo del lujo. Mientras que el resto de la humanidad se derrumbaba, él mantenía su integridad como productor de placer, comprador de oro y vendedor de ocio" (Asimov 2010: 409); y en ese mundo de ocio, "una escuálida figura que, con los pies en el aire, se paseaba sobre sus manos para divertir a un grupo de curiosos. Era uno de los numerosos mendigos acróbatas de la playa, cuyas flexibles articulaciones se doblaban y contorsionaban para ganar unas monedas" (Asimov 2010: 412).

Las diferencias geográficas "son mucho más que meros legados históricos y geográficos. Son perpetuamente reproducidas, sostenidas, socavadas y reconfiguradas por los procesos políticoeconómicos y socio-ecológicos que tienen lugar en el presente" (Harvey 2003: 98).

Asimov, residente en Nueva York (la ciudad que junto con la de Los Ángeles sirvió de base a Manuel Castells, en 1989, para ver la nueva configuración socioespacial y denominarla "ciudad dual"), describe en su Trilogía dualidades en y entre ciudades. El solitario planeta Haven es un espacio tenebroso, un mundo rocoso y con ciudades cavernosas, sin sol.

La ciudad-caverna que no puede compararse a la Fundación, pero es la ciudad más grande de Haven II. Tiene veinte mil habitantes. Creo que acabará gustándote. Lo siento, pero no hay parques de diversiones, aunque tampoco hay policía secreta. [...] La mayoría de las casas tenían dos pisos y estaban construidas con la piedra lisa de la región. Faltaban las torres de la Fundación y las colosales casas de comunidad de los Reinos Antiguos, pero había intimidad e individualismo; era una reliquia de la iniciativa personal de una Galaxia de vida en masa. (Asimov 2010: 385)

En una de sus fábricas trabajan Bayta y otras mujeres: "la producción ha descendido a una cuarta parte de lo que era cuando llegué, y ningún día acude toda la plantilla de obreras. [...] Y ocurre lo mismo en todo Haven. Baja de la producción, sedición e indiferencia por doquier" (Asimov 2010: 481, 487). 
Tazenda es "el extremo Estelar", ocupado por una oligarquía que "gobierna veintisiete planetas habitados. No está avanzado científicamente", donde "si alguna vez la historia fue una ciencia, se ha perdido completamente en esta región de la Galaxia" (Asimov 2010: 625). La Segunda Fundación podría estar en Tazenda, "un mundo ordinario, sin distinción, un arrabal perdido entre las ruinas de un Imperio" (Asimov 2010: 637). Y en este extremo de la Galaxia sitúa el autor el mundo agrícola, dependiente de Tazenda en sus transacciones comerciales -ya que "incluso las máquinas y los alimentos tanzedianos eran mejor que los productos nativos" (Asimov 2010: 639)- a cambio de madera y ciertos minerales. Ese mundo primitivo y de campesinos y pueblos es Rossem.

Parece evidente el protagonismo de la ciudad y los espacios urbanos en la Trilogía, si junto a las ciudades anteriormente citadas añadimos Gleiar City (Asimov 2010: 393), Siwenna que "ya no es capital del Sector Normánico" (Asimov 2010: 220), Newton, o Radole City. Nos preguntamos si fue intención del autor rendir un homenaje con la denominación de la ciudad de Newton a su homónimo Isaac Newton, que desarrolló entre otros descubrimientos una teoría sobre el origen de las estrellas. En ella se localiza la Atom-Field Bearings Inc., una corporación que fabrica escudos antiatómicos, "que necesita más obreros para elevar su productividad", controla su accesibilidad mediante "tarjetas de identidad" con su propio "distrito residencial", que lleva a sus obreros a "pasar las veladas en la ciudad", un área residencial levantada por la empresa solo para empleados, probablemente con semejante falta de atractivo a las que levantaron las compañías industriales a mediados del siglo XX y que tienen su réplica en los actuales polígonos empresariales, que solo brindan a sus empleados o bien sus propias instalaciones (restaurante, bar, tienda, etc.), o bien un hotel 0 un centro comercial ubicados en alguna manzana próxima.

Newton tiene igualmente un "barrio residencial que había sido elegante y que ahora ofrecía un aspecto mísero; la casa, una de tantas que bordean la calle; la habitación estaba en buen estado, pero carecía de lujo"; pero en esta habitación se localiza un "proyector de libros" cuya lente "podía ser controlada a distancia" y su morador ofrece comida de bote que se calienta al contacto con los dedos, mientras que el invitado puede desaparecer en cualquier momento: "No quedará más que una pequeña quemadura en el lugar donde está sentado si hay algo en usted que no me gusta. ¿Lo sabe?" (Asimov 2010: 497, 501). ¿No recuerdan estas frases a las viviendas no muy confortables, ocupadas por clases medias, llenas de los últimos artefactos que el mercado proporciona en la actualidad?

Radole City es un lugar estratégicamente situado. Su emplazamiento "a lo largo de las suaves laderas de las colinas", con 
un clima muy benigno en razón a las montañas que la protegen del frío y que le proporcionan agua:

Era un eterno jardín donde cada casa tenía su jardín florido. [...] Cada jardín era un lugar de horticultura forzada, donde las plantas de lujo crecían en fantásticas formas para ser exportadas al extranjero, hasta que atrajo a los extranjeros que llegaron de cada uno de los otros veintiséis mundos comerciantes: delegados, esposas, secretarios, periodistas, naves y tripulaciones, y la población de Radole casi se dobló. (Asimov 2010: 446)

¿Es acaso Radole City, el sueño del urbanita que vive en la mayor aglomeración (12 millones de habitantes) del mundo en los años cincuenta? Es posible, si tenemos en cuenta la vivienda de un radoliano, donde el nuevo amigo descansa "en la plataforma soleada, situada en la cima de una colina, lejos de las otras viviendas, aparentemente aislada en un océano de perfume floral y zumbido de insectos" (Asimov 2010: 449).

Centro y periferia urbana, con su distinto significado, se expresan por la localización de palacios, templos, teatro, universidad, e ideas: "venga al calor y la riqueza del centro" (Asimov 2010: 284). Es decir, el poder frente a "la paz de una casa de los suburbios" (Asimov 2010: 788). "La villa suburbana de Pherl" (Asimov 2010: 176), o "la casa suburbana del doctor Darell" (Asimov 2010: 755) representan en la obra diferentes tipologías residenciales.

La movilidad en la Galaxia es una hipermovilidad de la propia acción en la obra, que transcurre entre estrellas, planetas y diferentes ciudades; y se realiza mediante flotas espaciales o naves de distinta generación que utilizan espaciopuertos (Asimov 2010: 802) y cosmódromos (Asimov 2010: 755). Algunas de estas naves vuelan sin hombres; coches aéreos, coches de superficie, coches atómicos, taxis, aerotaxis, túneles o avenidas. Por otra parte, los distintos espacios están vigilados mediante "medidas de seguridad en el espaciopuerto" y vigilantes dotados de "látigos neurónicos" (Asimov 2010: 809), y en las viviendas hay "pantallas protectoras" frente a los intrusos (Asimov 2010: 709). Las medidas de seguridad evocan la sociedad del riesgo global que propone Ulrich Beck, basada en aspectos ecológicos y tecnológicos, y con implicaciones sociológicas y políticas (Beck 2000: 31). "Esta vigilancia extensiva crea un scanscape virtual, un espacio de visibilidad protectora" (Davis 2001: 9) frente al yo y los otros, junto al control urbano, mediante dispositivos que permiten seguridad y control, las tendencias hacia la militarización del paisaje (Davis 2003). En la obra de Asimov, la tecnología ha desarrollado cápsulas de mensajes de pequeño tamaño, impenetrables al análisis electrónico, que solo se abren con la característica personal del destinatario, "visífono público" (Asimov 
2010: 110). También aparecen "naves armadas con los habituales explosivos nucleares y campos de fuerza defensivos", "visiplacas", e incluso los caminos del espacio están unidos por una red tecnológica (Asimov 2010: 802), como hoy están conectados los caminos del ciberespacio.

Como conclusión, creemos habernos adentrado en la galaxia urbana de la Trilogía desde la plural geografía de hoy. Su lectura nos ha permitido observar diferentes ciudades; pasando páginas hemos recorrido distintos enclaves urbanos, que nos han llevado a comparar la ficción de Asimov con la realidad urbana de nuestro planeta. Efectivamente, en la imaginación del bioquímico y escritor había una galaxia ficticia, pero si obviamos ese espacio estelar y reducimos la escala a nuestro planeta, la ficción de hace seis décadas se convierte, hoy, en realidad. Es decir, la ciudad en la Galaxia de Isaac Asimov fue prospectiva; este hecho nos ha obligado a patear la realidad urbana actual y a deambular, en ocasiones muy precipitadamente, por nuestra propia ciencia. Por ello, estamos enormemente agradecidos a su narrativa y a su persona. 


\section{Bibliografía}

AA VV (2008): Post-it city. Ciudades ocasionales. Barcelona: Centre de Culture Contemporània de Barcelona.

AMENDOLA, G. (2000): La Ciudad Postmoderna. Madrid: Celeste.

ASIMOV, I. (2010): Trilogía de la Fundación. Fundación. Fundación e Imperio. Segunda Fundación. Barcelona: Debolsillo.

ATKEARNAY (2011): The A. T. Kearney global cities index 2010 [en línea]. En: http://www.atkearney.com [Consulta: agosto de 2011].

AZÚA, F. (2004): "La necesidad y el deseo", en AA VV, La arquitectura de la no-ciudad, pp. 171-195. Pamplona: Cátedra Jorge Oteiza.

BECK, U. (2000): La sociedad del riesgo global. Madrid: Siglo XXI.

BORJA, J. (2003): La ciudad conquistada. Madrid: Alianza.

BUZAI, G. (2004): "Geografía y tecnologías digitales del Siglo XXI: una aproximación a las nuevas visiones del mundo y sus impactos científico-tecnológicos" [en línea]. Scripta Nova, vol. VIII, núm. 170. En: http://www.ub.edu/geocrit/sn/sn-170-58.html [Consulta: agosto de 2011].

CARERI, F. (2002): Walkscapes. El andar como práctica estética. Barcelona: Gustavo Gili.

CARRERAS, C. (1998): "El uso de textos literarios en geografía", en Aurora García Ballesteros (coord.), Métodos y técnicas cualitativas en geografía social, pp. 163-176. Barcelona: Oikos-tau.

CASTELLANI, J. P. (2010): "Ficción en el paraíso: el cine", en Eugenia Popeanga (coord.), Ciudad en obras, pp. 173-186. Berna: Peter Lang.

CASTELLS, M. (1995): La ciudad informacional. Tecnologías de la información, reestructuración económica y el proceso urbanoregional. Madrid: Alianza.

- (2001): La Galaxia Internet. Barcelona: Plaza \& Janés.

CCCB (2008): "Post-it-City. Ciudades ocasionales". Centre de cultura contemporània de Barcelona. En: www.cccb.org [Consulta: agosto de 2011].

CENTRO ANDALUZ DE ARTE CONTEMPORÁNEO (2006-2011): Atributos urbanos [en línea]. En: http://www.atributosurbanos.es/glosario [Consulta: agosto de 2011].

CÓRDOBA, J. (1998): "Geografía y cine", en Aurora García Ballesteros (coord.), Métodos y técnicas cualitativas en geografía social, pp. 177217. Barcelona: Oikos-tau.

CORTÉS, J. M. (2010): La ciudad Cautiva. Control y vigilancia en el espacio urbano. Madrid: Akal.

DAVIS, M. (2001): "Más allá de Blade Runner". Control urbano: la ecología del miedo. Barcelona: Virus.

- (2003): Ciudad de cuarzo. Arqueología del futuro de Los Ángeles. España: Lengua de Trapo.

DODGE, M.; \& KITCHIN, R. (2001): Atlas of Cyberspace. London: Pearson. Disponible en: http://www.kitchen.org/atlas [Consulta: agosto de 2011].

ECHEVARRÍA, J. (1999): Telépolis. Barcelona: Destino.

FERNÁNDEZ DE ALBA, A. (2006): Palabras Sobre la ciudad que nace. Madrid: RAE. 
FERRÁS, C. (1999): "La ciudad dispersa y las aldeas virtuales. Los estudios geográficos y el retorno a la cultura", en AA VV, El Territorio y su Imagen, vol. II, pp. 1031-1041. Málaga: AGE / Departamento de Geografía de la Universidad de Málaga.

GÁNDARA, A. (2003): "Ya somos leyenda. La novela en la ciudad", en AA VV, Ciudades posibles, pp. 43-69. Madrid: Lengua de Trapo.

GARCÍA BALLESTEROS, A. (coord.) (1995): Geografía urbana. La ciudad: objeto de estudio pluridisciplinar. Barcelona: Oikos-tau.

GIBSON, W. (1984): Neuromancer. New York: Ace Books.

GÓMEZ DE SEGURA, J. et al. (2007): "Zaragoza virtual: la transformación de una ciudad" [en línea]. ACE, vol. 2, núm. 4, pp. 723-732. En: http://www.uocpapers.uoc.edu [Consulta: agosto de 2011].

GRAHAM, S. (1998): "The end of geography or the explosion of place? Conceptualizing space, place and information technology". Progress in Human Geography, vol. 22, núm. 2, pp. 165-185.

- (ed.) (2004): The cybercities Reader. London: Routledge.

GRAHAM, S.; \& MARVIN, S. (1996): Telecommunications and the city. Electronic spaces, urban places. London: Routdledge, $434 \mathrm{pp}$.

- (2001): Splintering urbanism. Networked infrastructures, technological mobilities and the urban condition. London: Routdledge.

GUTIÉRREZ, J. (1999): "La geografía del ciberespacio", en Lecturas Geográficas, vol. I, pp. 525-534. Madrid: Editorial Complutense.

- (2000): "La geografía del ciberespacio", en Lecturas Geográficas, vol. I, pp. 525-534. Madrid: Editorial Complutense.

- (2003): "El espacio geográfico y las nuevas tecnologías de la información y las telecomunicaciones", en M. Valenzuela (coord.), Un mundo por descubrir en el Siglo XXI, pp. 127-139. Madrid: Real Sociedad Geográfica.

INFANTAS, I. (2009): "Visión geográfica del ciberespacio" [en línea]. Ar@cne, núm. 117. En: http://www.ub.edu/geocrit/aracne/aracne117.htm [Consulta: agosto de 2011].

HALL, P. (1975): "Soft City. By Jonathan Raban". The Geographical Journal, book review, vol. 141, núm. 1.

HARVEY, D. (1990): The condition of postmodernity: an enquiry into the origins of cultural change. Oxford: Blackwell.

- (2003): Espacios de esperanza. Madrid: Akal.

JUARISTI, J. (1999): "La postmodernización como estrategia de revitalización urbana: aprendiendo de Bilbao", en AA VV, El Territorio y su Imagen, vol. II, pp. 1085-1097. Málaga: AGE y Departamento de Geografía de la Universidad de Málaga.

LÓPEZ, O. (2007): "Herramientas bibliográficas para pasear por la ciberciudad" [en línea]. UOC, núm. 5. En: http://www.uocpapers.uoc.edu [Consulta: agosto de 2011].

LÓPEZ, O. et al. (2009): "Visión geográfica del ciberespacio" [en línea]. Ar@cne, núm. 117. En: http://www.ub.edu/geocrit/aracne/aracne117.htm [Consulta: agosto de 2011].

LUKE, P. (2008): "Mumbai: the soft city" [en línea]. New Statesman, vol. 137. En: http://www.newstatesman.com/asia/2008/12/city-bombaymumbai-modernism [Consulta: agosto de 2011]. 
MITCHELL, W. (2001): e-topia: vida urbana, Jim, pero no la que nosotros conocemos. Barcelona: Gustavo Gili.

MORENO, F. Á. (2010): Teoría de la literatura de la ciencia ficción. Poética y Retórica de lo prospectivo. Vitoria: Portal.

OMT (2011): Panorama OMT del turismo internacional [en línea]. En: http://www.unwto.org/facts [Consulta: septiembre de 2011].

PACIONE, M. (2001): Urban Geography a global perspective. London: Routledge.

PEÑA, M. (2002): "La ciudad en la ciencia ficción: La literatura como ilustración y contraste de la teoría" [en línea]. Revista de Estudios sociales, núm. 11. En: http://www.redalyc.uaemex.mex [Consulta: julio de 2011].

PIKE, B. (1981): The image of the city in modern literature. Princeton: University Press.

PILE, S.; \& THRIFT, N. (2000): City a-z. London: Routledge.

PILE, S.; BROOK, C.; \& MONEY, G. (1999): Unruly Cities? Order/Disorder. London: Routledge / The Open University.

PONCE, G. (2011): "Futuro imperfecto: las ciudades del mañana en el cine". Boletín de la Asociación de Geógrafos Españoles, núm. 55, pp. 127152.

POPEANGA, E. (coord.) (2010): Ciudad en obras. Berna: Peter Lang.

RABAN, J. (1974): Soft City. London: Hamish Hamilton.

SASSEN, S. (1991): The Global City. New York, London, Tokyo. Princeton / New Jersey: Princeton University Press.

SOJA, E. (2008): Postmetrópolis. Estudios críticos sobre las ciudades y las regiones. Madrid: Traficantes de Sueños.

UNHABITAT (2011): The state of African cities 2010. En: http://www.unhabitat.org [Consulta: agosto de 2011].

VIVAS, P. et al. (2008): "Barcelona una ciberciudad en tránsito". ACE, año II, núm. 6, pp. 723-732. En: http://www.cpsv.upc.es/ace/Articles [Consulta: agosto de 2011]. 